\title{
RUBENS EN LA PINTURA NOVOHISPANA DE MEDIADOS DEL SIGLO XVII
}

\author{
José Rogelio Ruiz Gomar C
}

La producción pictórica de las escuelas hispanoamericanas durante la etapa colonial presenta un carácter peculiar que, a grandes rasgos, podría entenderse como el resultado de un constante proceso de amalgamación y adaptación que consistió, básicamente, en la capacidad para reelaborar y matizar los logros y novedades que por diversos caminos llegaban del Viejo Mundo, con las tradiciones localistas y lo que cabría llamar como un gusto propio, mismo que ya desde la segunda mitad del siglo XVI estaba en vías de formación, como respuesta a las peculiares condiciones y características aquí existentes

Cierto que para un ojo poco avezado y familiarizado en estos menesteres resulta algo difícil reconocer bajo las amables creaciones de los pinceles novohispanos, limeños o cuzqueños la huella de los maestros europeos, e incluso se ha dado al fenómeno una carga peyorativa y se le ve con cierto menosprecio, pero, tal y como alguien apuntara, no deja de ser una aventura cautivante el poder detectar la presencia tanto de artistas de renombre, como de maestros de talla modesta, ya italianos, flamencos o españoles, en la producción pictórica de este lado del océano. En el caso concreto de la pintura de la Nueva España, son significativos, por ejemplo, los casos de artistas que, como Martín de Vơs, Zurbarán, Rubens, Murillo y Valdés Leal, se constituyeron en atrayentes modelos a seguir.

El propósito de estas líneas es el señalar y destacar la presencia en la pintura novohispana de hacia mediados del siglo XVII del genial maestro del movimiento y el color, Pedro Pablo Rubens. Me limitaré al ámbito mexicano y al tiempo expresado, pero es obvio y por todos conocido, que su impacto se dejó sentir por toda hispanoamérica y perduró vigente hasta bien entrada la centuria décimo-octava.

Rubens, uno de los artistas cimeros del arte barroco del siglo XVII, fue un hombre con quien la vida se mostró magnánima. No sólo le dotó de un poderoso talento artístico, sino que, además, le rodeó de éxitos, fama y todo tipo de honores aun en campos ajenos a su oficio de pintor. Trabajador incansable, su arte es de un ímpetu avasallador y fulgurante, de un goce creador arrogante y vivaz. Su fastuosa y prolija producción nos revela un mundo de formas nacidas y vividas a través de la belleza y de la felicidad

Su obra gozó de un enorme prestigio por casi todo el mundo europeo, y a nadie escapa que con su vigoroso estilo coadyuvó enormemente a la renovación que vivía el arte de su tiempo. Mas, es el caso de que, como ya apuntábamos, el impacto de su genio creador tuvo importante resonancia en el arte que se producía en las remotas tierras del mundo americano, y ello desde me- 
diados de la misma decimoséptima centuria, por muy temprano que ello pueda parecer Cabe señalar que fueron los grabados el medio eficaz por el cual este artista se hizo presente en casi todos los círculos artísticos; y si bien en Europa misma, las estampas jugaron un importante papel en la transmisión del repertorio de su extensa obra, el fenómeno se acentuó notablemente para el caso de América. ${ }^{\prime}$ Así las cosas, debemos convenir que la presencia de Rubens en el Nuevo Mundo, se redujo principalmente a dos caminos: al ya senalado de los grabados, que reproducían sus dinámicas composiciones, y al de las pequeñas láminas y grabados flamencos de seguidores de su estilo. No está de más recordar que, acaso con más ingenuidad que conocimiento efectivo, se han reputado como suyas varias obras existentes en México desde tiempos de la Colonia, verbigracia, la serie de láminas que se guardan en San Juan de los Lagos, Jalisco, ${ }^{2}$ o las que según Revilla existian en el retablo mayor de la capilla de la Virgen de las Nieves, en la iglesia del convento de monjas concepcionistas de Regina Coeli y "que el capellán de dicha iglesia mandó quitar para vendérselas al coronel italiano Guccioni que aun las tiene en su poder", 3

Con todo, creo que no se ha insistido lo suficiente en la importancia que de-" sempeñó en todo este proceso el grabado, y considero que, ya en esta dirección, habría que hablar más del esfuerzo llevado a cabo por Rubens para convertir la estampa en un cuadro grabado

A partir de la invención del papel fue posible la aparición de la estampa, misma que nació en imágenes de piedad y naipes, esto es, con origen de irradiación religiosa y de diversión. Podemos decir, sin embargo, que para fines de la Edad Media, el grabado se había constituido en el arte de la gente modesta, como paralelo de la miniatura aristocrática, y se vendía suelto o en colecciones, en ferias, mercados y a las puertas de la iglesia ${ }^{4}$

Pronto los artistas mostraron interés por este nuevo medio de expresión que resultaba ser, por su multiplicidad, bajo costo y su facilidad para transportar y archivar, un excelente recurso para la difusión de las artes y la transmisión

1 Baste pensar que, a diferencia de otros artistas, como pueden ser los flamencos Martín de Vos y Simón Pereyns, los italianos Angelino de Medoro, Bernardo Bitti y Mateo Pérez de Alesio, o los españoles Alonso Vásquez y Francisco de Zurbarán, todo el impacto de su arte nos llegó a través precisamente y casi de manera exclusiva de los grabados Rubens ni pasó a estas tierras ni, hasta donde sabemos, vinieron obras originales suyas, ni llegaron discípulos directos.

"Iid. Leopoldo I Orendain, "Los presuntos Rubens de San Juan de Los Lagos", en Anales del Invilute de Imrertigationes Estéthas, Vol VI, No 23, México, UNAM, 1955

${ }^{3}$ Manuel (;. Revilla, El arte en Mévuo en la éprer a antigua y durante el gobierno cirreinal, México, 1893, p. 72. Este autor menciona, asimismo, entre las obras europeas que pasaban el océano y eran copiadas por los pintores coloniales, un buen número de pequeñas láminas "muchas de ellas de Rubens", noticia que debe tomarse con las debidas reservas

$+\mathrm{Nl}$ decir de Arnold Hauser, los grabados, ya en madera, ya en cobre, fueron los primeros productos populares y relativamente baratos del arte; su reproducción mecánica per mitió que alcanzara una mayor difusión, con lo que el arte no sólo dejó de ser elitista, sino que colaboró en el proceso de considerar la obra de arte como una mercancía. Histona sacial de la literalura y el arte, Madrid, 1962 , t 1, p. 273-274 
de las imágenes y las ideas Así, no extraña que en poco tiempo adquiriera un lugar preponderante en los talleres como instrumento de aprendizaje y de recopilación tanto de temas como de formas ${ }^{5}$

A partir de mediados del siglo XV encontramos a algunas importantes figuras interesadas en las posibilidades expresivas de este nuevo lenguaje plástico. En Italia tenemos los casos de Mantegna (Padua), Baldini, Botticelli y Pollaiulo (Florencia); en Alemania, después del "Maestro de 1466", fundador de la escuela de grabado de aquel país, descolla Martín Schongauer, y poco después Durero y Holbein, quienes alcanzaron un alto dominio técnico; en los Países Bajos están Lucas de Leyden, Cornelis Cort, los Wierix, Goltzius y varios más

Debemos tener presente, empero, que en esta primera época los grabadores producen sus estampas utilizando los dibujos que buenamente les son proporcionados por los pintores; no ha llegado aun el momento en que éste solicite la colaboración de aquél Sería hasta la siguiente generación cuando se iniciaria aquel fértil diálogo entre la pintura y el grabado, apareciendo, así, el grabado que reproduce las composiciones de los artistas destacados ${ }^{6}$ Estos grabados de reproducciones (a diferencia de los grabados originales que respondía a la creatividad de importantes artistas, llámense Schongauer o Durero) han sido considerados injustamente como obras de simple labor artesanal de imitación; como la simple traslación de una pintura mediante el trazo del buril, o cualquier otro método al blanco y negro. Mas la verdad es que debemos ver en tales grabados de reproducción, un género artístico propio que resultaba de la conjunción de dos personalidades que poseían lenguajes diferentes, cuya confluencia daba lugar a la creación de obras hermosas, técnicamente perfectas y estéticamente originales.

Fue Rafael, con la ayuda de un discípulo suyo, Marco Antonio Raimondi, el primero en buscar la reproducción de sus obras, al comprender que con la utilización y explotación de este medio podría acrecentar su fama, obtener un ingreso adicional y satisfacer la creciente demanda por conocer su arte en los círculos artísticos europeos. ${ }^{7}$ Por su parte, Holbein, tras algunos inicios decepcionantes y mediante la formación de un ayudante que supo someterse a sus concepciones, logró buenos grabados que no demeritaban sus dibujos ${ }^{8} \mathrm{Al}-$

5 Iid Francisco Stasny, La presencia de Rubens en la pintura colonial, Lima, 1965, p 4. Este acucioso investigador peruano incluyó en su estudio, amén de una completa revisión de la influencia de Rubens en la pintura sudamericana, un interesante panorama general de los antecedentes del grabado y su empleo en la época de Rubens, es por ello que remito al lector a la lectura del mismo, pero me permito entresacar aquí algunos de sus planteamientos.

6 Ibulem, p. 5 . Como atinadamente señala Stasny, la única manera que por mucho tiempo hubo de conocer una pintura célebre, era visitando la colección del gabinete de estampas local; alli, en grandes volumenes, se encontraban grabadas por pacientes artesanos las Estancias del Vaticano, los grandes murales de la Sixtina, y todas las obras maestras que habian sido creadas desde los tiempos de Giotto o antes

7 Ibulem, p. 5.6

* Paul Westhaim, Ll grabado en Madera, México, 1967, p. 132 
gunos años más tarde, en Venecia, Tiziano impulsó con un grupo de colaboradores un verdadero renacer de la xilografía, y para ensayar la modalidad del grabado en cobre llamó a su lado al flamenco Cornelis Cort, quien permaneció un año en su casa (1565) y grabó una docena de magníficas planchas.

Pero no sería sino hasta medio siglo después que se produciría en la ciudad de Amberes el encuentro más fecundo e importante entre la pintura y la estampa; encuentro que repercutiría no sólo en la corriente artística de la época, sino incluso en una profunda renovación técnica del grabado y en la extensión de éste El autor de esta transformación, es fácil adivinarlo, fue precisamente Pedro Pablo Rubens.

Rubens no pretendía otra cosa que disponer de buenas versiones grabadas de sus obras, en base seguramente al antecedente de Rafael y de Tiziano; el resto, señala Francisco Stasny, lo haría el vigor inagotable de su temperamento artístico y su enorme capacidad de trabajo en equipo. ${ }^{9}$ Tras infructuosos resultados obtenidos con los grabadores de las escuelas de Amberes y de Harlem, Rubens comprendió que la única manera de conseguir lo que deseaba era enrolar a los artistas a su taller y dirigir personalmente su trabajo. El primero en aproximarse a las aspiraciones del maestro fue Pierre Soutman, pero quien realmente intuyó lo que el pintor quería fue Lucas Vorsterman, un joven que ingresara al taller como aprendiz de pintor, y al cual Rubens convenciera dedicarse mejor al arte del grabado. Bajo la dirección del maestro reprodujo algunas de sus obras maestras, y a diferencia de lo que había sucedido con la escuela de Harlem, la perfección del buril ya no se destacaba como una ostentación de virtuosismo, sino que desaparecía para dar lugar exclusivamente a una expresión cabal de la realidad pictórica La multiplicación de las líneas, la variedad de los entrecruces y el trazo sinuoso de las tallas con eficaces variaciones en la profundidad y el grosor de su incisión, expresaron como nunca lo habían hecho hasta entonces, la textura de los materiales, los juegos de luces y sombras y el valor de los colores, gracias a la sutileza infinita en la graduación de los grises que transponían correctamente las intensidades cromáticas ${ }^{10}$

La escuela estaba formada, de tal suerte que aunque la colaboración de Vorsterman y Rubens duró poco ${ }^{11}$, se estableció la continuidad con la labor de Paul Pontius, alumno de Vorsterman y la de la copiosa serie de grabadores que vino a continuación, encabezada por los hermanos Boetius y Schelte a Bolswert, Nicolás Lauwers y Nicolás Ryckman. La meta había sido alcanzada; a partir de entonces el estilo rubeniano se difundió por todos los ámbitos a través de las numerosas estampas que salieron de dicha escuela, mismas que

\footnotetext{
${ }^{9}$ Op. att, p. 7

10 Ibidem. p $9-10$

${ }^{11}$ Enemistado con el maestro, pasó en 1624 a Inglaterra y alli per maneció seis años trabajando para Carlos I y personalidades de la corte A su regreso a Amberes, trabó amistad con Antonio Van Dyck, quien también ya se había independizado del taller de Rubens, y reprodujo muchas de sus obras
} 
repetian las composiciones de la vastísima producción del maestro, que comprendía indistintamente escenas religiosas, temas históricos o costumbristas, alegorias, paisajes, escenas de cacería y asuntos mitológicos.

A la muerte de Rubens las numerosas planchas que reproducian sus composiciones fueron pasando de editor en editor, y taller en taller, así casi hasta nuestros días. Pero hay que hacer hincapié en que poco a poco la escuela empezó a abarcar a muchos más que el reducido círculo de artistas que trabajaron bajo el techo del maestro, y se inició aquella reacción en cadena, aquella multiplicación de copias y de las copias de copias, que plagian las grandes composiciones, reduciéndolas, desvirtuándolas e invirtiéndolas Abundante producción que nos habla, por otra parte, de la popularidad que gozaba la obra de Rubens y de la amplia difusión de sus estampas.

Regresando al tema central que nos ocupa, esto es, al estudio y revisión de la presencia de Rubens en la pintura novohispana de mediados del siglo XVII, vale apuntar que serían los principales representantes de este período, artistas de la talla de Sebastián de Arteaga, José Juárez, Pedro Ramírez y Baltasar de Echave y Rioja, los que aprovecharon con buena fortuna las composiciones del genial maestro flamenco

Iniciaremos nuestro cometido refiriéndonos a una pequeña lámina firmada por Baltasar de Echave Ibía que representa La Sagrada Familia. Este artista fue rescatado del olvido por don Manuel Toussaint, ignorado como estaba a la sombra de su padre y de su propio hijo. Si bien carece de una personalidad tan vigorosa como la de su padre, el gran Echave Orio, no se puede negar que posee, a cambio, una vena lírica llena de frescura. Su obra nos revela a un artista ecléctico que recogió la tradición de los pintores que le precedieron y que al mismo tiempo supo abrirse y mostrarse sensitivo hacia las novedades y los cambios en la rosa de los gustos. Aunque trabajó telas de regulares dimensiones, parece que prefirió la labor en pequeñas láminas de cobre. Sus pinturas se caracterizan por la inclusión de fondos de paisajes, delectación en tonalidades azulosas - lo que permitió le bautizara don Manuel como "el Echave de los azules"-, y por el carácter veneciano de algunos detalles ${ }^{12}$

El cuadro de La Sagrada Familia, tal y como señaló el doctor de la Maza, exhibe una marcada cercanía con el estilo de Rubens, aunque para este caso no haya sido localizada ni la obra original ni el grabado que debió servir como modelo. En ella podemos ver a María sentada con el Niño Jesús parado sobre sus piernas, quien, desnudo, la abraza por el cuello y posa una mano sobre su pecho; ocultos parcialmente aparecen, también, la señora Santa Ana y San José ${ }^{13}$ Los tipos de los personajes son marcadamente flamencos, a excepción

12 [ id. Gibson Danes, "Baltasar de Echave Ibia Some critical notes on the Stylistic character of his art", en Anales del Instituto de Investigactones Estéticas, No. 9, México, UNAM, 1942

${ }_{13}$ Puede verse reproducción de esta bella obra en La pintura mexicana Siglos XVI-XVII Colecciones particulares, México, 1966: llustración No 52, acompañada de un texto firmado por don Francisco de la Maza. (Mide $36 \times 31 \mathrm{~cm}$ y está registrada en la colección de Manuel Pérez Salazar). 
quizá del san José, representado con una mayor soltura y amabilidad; la Virgen María, con el pelo recogido, acusa el ideal de belleza femenino de Rubens; por su parte el niño Jesús presenta un cuerpecillo bien dotado de carnes que, afortunadamente, no llega a los excesos tan frecuentes en la obra del maestro flamenco; y no se diga la Santa Ana, que incluso recuerda a Isabel Brandt, primera esposa de Rubens. Asi pues, Echave siguió tan obedientemente el modelo que, tal y como observara el doctor de la Maza, llegó a esa desenfadada libertad, tolerada en Rubens, de presentar un seno desnudo de Maria

Se desconoce la fecha de muerte de Echave Ibia, pero se acepta que floreció entre 1620 y 1640 . Si el cuadro que nos ocupa es realmente suyo - pues cabria la duda de que se tratara de una obra temprana de su hijo, Echave y Rioja-, habrá que aceptar que la influencia de Rubens se dejó sentir en estas latitudes desde la cuarta década del siglo XVII, quizá aun en vida del gran maestro, quien murió justamente en 1640 .

Nos ocuparemos a continuación del artista sevillano Sebastián López de Arteaga, quien viniera a México alrededor del año de 1640, acaso en el séquito del virrey Marqués de Villena que llegó precisamente en dicho año. Su padre, un platero de oro, murió cuando él apenas contaba con unos meses de nacido, por lo que un conocido de la familia le llevó a Ecija, donde estuvo hasta 1620 en que tuvo que volver a Sevilla. Años más tarde contrajo matrimonio con una sobrina suya y en 1633 aún estaba en Sevilla, donde era maestro de pintura; aparece avecindado en el puerto de Cádiz hacia 1638 y para 1642 lo encontramos ya en la Nueva España ejecutando el Arco Triunfal que se levantó a la entrada del virrey Conde de Salvatierra: En 1643 manifestó sus deseos de servir y realizar trabajos como pintor de imaginería al Santo Tribunal de la Inquisición, de lo que consiguió le fuese extendido el nombramiento de notario y recibiese el encargo de pintar los retratos de 19 inquisidores. Este pintor trajo a México un vigoroso estilo plástico, lleno de realismo y de vivos contrastes de luces y sombras; estilo de evidente ascendencia zurbaranezca. Su producción en la Nueva España no fue muy prolífica, pero sí de elevada calidad, aunque también hay que reconocerlo, bastante desigual, al grado de que, pese a estar firmados, más de un cuadro se ha puesto en duda su autenticidad.

El cuadro que ahora nos interesa es el de La Estigmatización de San Francisco de Asís firmado por Arteaga en 1650 que se conserva en el Museo de la Basílica de Guadalupe, en la ciudad de México. El lienzo sigue bastante de cerca el modelo rubeniano de la estampa grabada por Lucas Vorsterman que copia el cuadro del maestro que actualmente custodia el Museo de Colonia. La figura del santo es la misma, sólo que está un poco menos inclinada y Arteaga le ha suavizado el rostro, le ha reducido la barba y ha modificado levemente los gestos de las manos. Curiosamente, mientras que Rubens plasmó en el hábito del santo de Asís una serie de parches de tonalidades diversas, mismas que Vorsterman no pudo, o no quizo traducir fielmente a su plancha, Arteaga, que sólo pudo partir del grabado, no insistió en ese detalle y se concretó a seccionar el 
hábito mediante retazos que quedan unidos por burdas costuras Quizá el cambio más evidente entre obra y modelo es el del fraile que asiste como testigo al portento, pues mientras en el modelo grabado aparece en primer término casi recostado en la parte baja, en la versión de Arteaga queda dispuestc en un plano ligeramente más profundo hacia el lado izquierdo, acaso para no distraer al espectador con una figura tan vigorosa en sitio tan destacado. En cambio, del serafín de las seis alas, que no es otro que la imagen de Cristo en la cruz, Arteaga realizó una transcripción bastante fiel, quizá un poco más dura; sólo que al parecer no supo "leer" bien la luminosidad o resplandor que despide esta figura, pues mientras en el modelo está senalada por ráfagas que interrumpen las frondas de la vegetación en el peñasco que sirve de fondo al san Francisco, Arteaga terminó por suprimirla, dejando una sencilla representación del cielo. Asimismo, en tanto que en el modelo es fácil de advertir una rústica techumbre en la parte superior del peñasco, en el cuadro de Arteaga dicho cobertizo queda apenas insinuado.

A las diferencias señaladas entre ambas versiones habrá que añadir la inclusión que hizo Arteaga de unas rosas en la parte baja que no aparecen en el original, con las que imprime amabilidad a su cuadro, aunque pudiera ser que encerraran algun significado o simbología que a mí se me escapa; del mismo modo, incorporó hacia el lado izquierdo una vista de paisaje que no tiene correspondencia en el grabado; eliminó la lagartija que aparecía en el suelo y transformó el robusto tronco del primer término en uno más delgado entretejido con un rosal. También prefirió cambiar de lugar algunos atributos, y así, el cráneo que aparecía en el modelo hacia el lado derecho, ahora queda localizado debajo del libro. Curiosamente modificó también la caída del cordón en el hábito del santo, y esto porque debiendo pender por el lado derecho, el grabado, que invertía la composición, lo presentaba cayendo por el lado opuesto, y Arteaga tuvo que hacer la corrección pertinente. Por último, la mano izquierda de San Francisco ahora aparece con los dedos un poco más juntos y ligeramente flexionados

Detalles más, detalles menos, es evidente que Arteaga compuso su obra en base al modelo señalado o alguno que a su vez lo repetía. Sin embargo, más que todos estos detalles u otros que pudieran indicarse, el cambio de verdadera importancia está en el diferente espíritu que emana de la versión novohispana En términos generales pudiera decirse que es una transcripción menos vital, más suave, más amable que la propuesta en el modelo. El asunto es el mismo, pero mientras que en Rubens el acento se carga en lo grandioso del suceso, en la tela mexicana no hay cabida para drama ni excesivo boato; allá se nos hace partícipes de un portento único e irrepetible, acá se diría que asistimos a un acontecimiento poco solemne y cotidiano. Quisiera llamar la atención sobre la transformación tan notable, y aparentemente sin razón, del rostro del santo entre el modelo y la copia. ¿ Podria pensarse que fue por falta de capacidad que Arteaga no pudo repetir ese mismo rostro? Evidentemente que no. La respuesta debe buscarse en el hecho de que Arteaga no podía sustraer- 
se al mundo español al que pertenecía; y si a esto agregamos el que hubo de incorporarse al medio artístico novohispano, que poseía ya un gusto y una tradición icónica propia, concluímos que la mutación obedeció a la necesidad de adaptar su propio estilo a las exigencias iconográficas existentes en estas latitudes, toda vez que la representación del santo de Asís gozaba en este medio no sólo de una gran devoción, sino también de una larga tradición en su representación, lo que significa que habia que plegarse a una imagen por todos reconocible y aceptada. Así pues, no es que Arteaga no entendiera el modelo y confundiera la abundante barba que muestra el modelo con la caperuza de su versión; no, sólo le dió el rostro que le era familiar en el ambiente español, y mejor aún en el novohispano, al cual él ya se había asimilado; por este mismo fenómeno es que Arteaga le dotó de la aureola que le faltaba al original.

Pasemos ahora a ver el caso ya estudiado por el doctor Justino Fernández ${ }^{14}$ del pintor José Juárez, el pintor novohispano más destacado de su época, cuyo cuadro de la Sagrada Familia con una paloma, fechado en 1655, y que se conserva en la Academia de Bellas Artes de Puebla, está sacado del grabado que sacó Martín van den Enden del cuadro que del mismo tema ejecutó Rubens, o de alguna copia de éste. ${ }^{15} \mathrm{El}$ cuadro de Rubens, como dijera don Justino, resulta atrayente "por la gracia incomparable de las actitudes, la frescura del colorido y la elegancia y libertad de sus líneas". Remito al lector al estudio hecho por el Doctor Fernández para analizar el estrecho vínculo que existe entre las obras mencionadas, pero me permito traer a cuenta algunas de sus consideraciones, así como sus conclusiones. Rubens realizó su cuadro hacia 1609, ya de regreso en Amberes después de su viaje por Italia. En él presenta una escena llena de intimidad y de alegría; todos los personajes sonríen; los niños con natural y juguetona actitud, los demás con bondadosa delectación. Ningún detalle es superfluo, de manera que la atención se centra en los personajes, en sus actitudes y ropajes Las líneas de la composición fluyen con dinámica y barroca elegancia. Por su parte Juárez nos entregó una tela de mayores dimensiones, un tanto desangelada, de factura más blanda y débil en su composición; esto último por las libertades que se permitió, pues no contento con añadir la figura de san Joaquín, llenó el fondo con formas arquitectónicas, cortinajes y un paisaje en último término; detalles, estos, con los que, si bien le imprimió a su versión una mayor teatralidad, también le restó la espontaneidad que prevalecía en el modelo, y dispersó la atención en una mayor cantidad de elementos. Por lo que respecta al ambiente psicológico, éste también quedó alterado.

\footnotetext{
14 Justino Fernández, "Rubens y José Juárez", en Anales del Instituto de Investigaciones Estéticas, No 10, México, UNAM, 1943.

${ }^{15}$ Ibidem, p. 56. Al respecto conviene traer a cuento lo apuntado por Abelardo Carrillo y Gariel: "El critico don Justino Fernández cree que se trata de una inspiración directa a través de un antiguo grabado que reprodujo la "Sagrada Familia", atribuida a Rubens... Me opongo a esta idea por el esfuerzo inútil que hubiese representado el que José Juárez invir tiese ese grabado y me inclino a continuar considerándolo como tomado de una copia". (Técnica de la pintura de Nueva Espa$\tilde{n} a$, México, UNAM, 1946, p 157)
} 
Mientras que en la escena de Rubens bulle la alegría y se respira la intimidad en la de Juárez se capta una bienechora paz, pero nadie sonríe, y cuando más podría decirse que sus personajes respiran serenidad Además, el dinamismo de Rubens se convierte en Juárez en un barroquismo más severo, más español que italiano; la atmósfera resulta más estática y decorativa, y las líneas no fluyen con tanta libertad. Las figuras han ganado en sencillez pero han perdido en lozanía. En resumen, Juárez logra una buena tela pero acorde al gusto que privaba en el ambiente en que él se desenvolvía. Toma como punto de partida el modelo rubeniano, pero desemboca en una versión libre y totalmente distinta, apegada a la tradición y predilección artística de la Nueva España. La conclusión del Doctor Fernández es bastante objetiva: "Ya pueden deducirse - afirma- las grandes semejanzas y diferencias que tienen ambas obras: más decorativa, teatral, moderada y convencional, la de Juárez; más vital, realista, dinámica, atrevida y elegante la de Rubens" ${ }^{16}$ Así pues, la simplificación de paños, la modificación de actitudes, el prurito por no evidenciar demasiado las desnudeces en el niño Jesús y el pequeño Juanito, el importante cambio en el tipo del San José, la ambientación de la escena con la canasta de frutas, el cortinaje, la arquitectura y el paisaje del fondo, etc., son expedientes que acusan la personalidad de nuestro pintor. No se trata de insuficiencia de su parte si no sigue el modelo; lo que sucede es que toma el tema y la composición que le proporciona el modelo, pero los interpreta según los medios expresivos propios, los traduce a su peculiar lenguaje plástico, mismo que, no podía ser de otra manera, responde a las tradiciones formales y al gusto imperante en su medio y época.

Este ejemplo localizado por el Doctor Fernández es muy ilustrativo, pero de ninguna manera fue un caso aislado en la obra de Juárez. Es probable que con el tiempo se sigan identificando más antecedentes como éste; recordemos tan sólo la relación formal entre una figura, o quizá un grupo de figuras que aparecen en un cuadro de Rubens que ilustra un Milagro de San Francisco Javier (Museo de Viena), y el fragmento sumamente maltratado de lo que queda de un cuadro de la vida del beato Sebastián de la Horta de Juárez que se conserva en la bodega de la Pinacoteca Virreinal. ${ }^{17}$

Vayamos ahora con el enigmático Pedro Ramírez, activo también a mediados de la centuria decimoséptima, quien copió las composiciones rubenianas del Triunfo de la Eucaristía y La Eucarsstía y los sacrificios del paganismo para las telas que se localizan actualmente en la catedral de la ciudad de Guatemala; cua-

\footnotetext{
16 Ibudem. p 55.
}

17 A esta misma relación formal se refiere Abelardo Carrillo y Gabriel (op.cil, p 157) cuando expresa: " ... el óleo que representa a San Salvador de Borra (sic) curando en Montserrate atribuido actualmente a José Juárez, reproduce todo el primer término, invertido por el grabado, de la pintura de Pedro Pablo (Rubens) que tiene por asunto los milagros de San Francisco Javier, existente en el Hofmuseum de Viena; la obra mexicana no tiene modificado sino el fondo, los per sonajes del último término y la figura del santo, a menos que se trate de una lámina que se refiere a una composición desconocida" 
dros que con toda seguridad fueron realizados en Nueva España y luego enviados a aquellas tierras. Como tales temas fueron repetidos mas de una vez en el ámbito novohispano, ${ }^{18}$ bien valdría la pena hacer un poco de historia Dichas composiciones son parte de la serie de 17 diseños que encargó a $\mathrm{Ru}$ bens la princesa Isabel Clara Eugenia, hija de Felipe II, para modelo de una tapicería, con el tema de "La Apoteósis Eucarística" destinada a engalanar el convento de las Descalzas Reales en la ciudad de Madrid. La serie se terminó en 1628, y se hicieron grabados sueltos de varias de las composiciones. ${ }^{19}$

El convento de las Descalzas Reales fue fundado por una hija de Carlos V. En él ingresaron, ya con reclusión voluntaria pero sin votos, o como verdaderas religiosas, algunas importantes mujeres de la corte española; tales los casos de la Emperatriz Maria, hermana mayor de Felipe II, tía y suegra a la vez de Clara Eugenia, y la archiduquesa Margarita, hija de la emperatriz Asimismo, la Infanta Isabel Clara Eugenia, de niña y jovencita, había pasado en dicho convento largas temporadas y asistido a las principales festividades del año religioso. Este convento celebraba al año dos procesiones claustrales, pero solemnísimas, una, en la octava del Corpus Christi, y la otra el Viernes Santo. Para esta última gozaba el convento del privilegio especial de una procesión eucarística, en un día en que litúrgicamente estaba dispuesto se asumieran por la mañana del Jueves Santo las hostias consagradas y se mantuviera visible la desolación del sagrario vacio. En tal ocasión se llevaban en una hermosa imagen tallada por Gaspar Becerra, en el paso del Santo Entierro, el Sacramento visible dentro de la llaga del costado, incrustado como relicario. Felipe II había dejado dispuesto que para tal solemnidad la Casa Real procurara todos los años tapices con qué engalanar el claustro Pero Isabel Clara Eugenia decidió encargar una espléndida y nueva serie de tapices, aprovechando que tenía en flandes los más afamados tapiceros del Mundo, y en Amberes a Rubens, el pintor de mayor fama a la sazón del mundo, con quien cultivaba una amistad personal. ${ }^{20}$

Las pinturas de Pedro Ramírez en la catedral de Guatemala reproducen las composiciones de los cuadros de Carro Triunfal eucarístico de la Iglesia y La Eucaristía y los sacrificios del paganismo.

18 Aparte de las pinturas de Pedro Ramírez en la catedral de Guatemala, estas composiciones fueron repetidas por Baltasar de Echave y Rioja en la sacristía de la catedral de Puebla - que veremos a continuación-, por Juan Correa, en un cuadro existente en la ciudad de Monterrey, y por Cristóbal de Villalpando en las grandes telas de la sacristía de la catedral de México y en un lienzo que pertenenece al Museo Regional de Guadalajara. Existe, además, un cuadro con el mismo asunto en la iglesia de Santo Domingo, en Puebla, que por la altura a que está colgado es imposible saber si está firmado

19 Iid Elias Tormo, "La Apoteosis Eucarística de Rubens", en Archivo Español de Arle, No 49, Madrid, enero-febrero, 1942, p 7 Rubens se empenó en que fuesen grabadas diez de las once primeras creaciones de la serie, las a su juicio principales, y las más propias para su venta aislada. Las planchas de Schelte a Bolswert y de Nicolás Lauwers de esta serie, se cuentan entre las obras maestras de la escuela rubeniana de grabado

20 Ihatem, p. 4-5 
DOI: http://dx.doi.org/10.22201/iie.18703062e.1982.50\%20Tomo\%201.1140

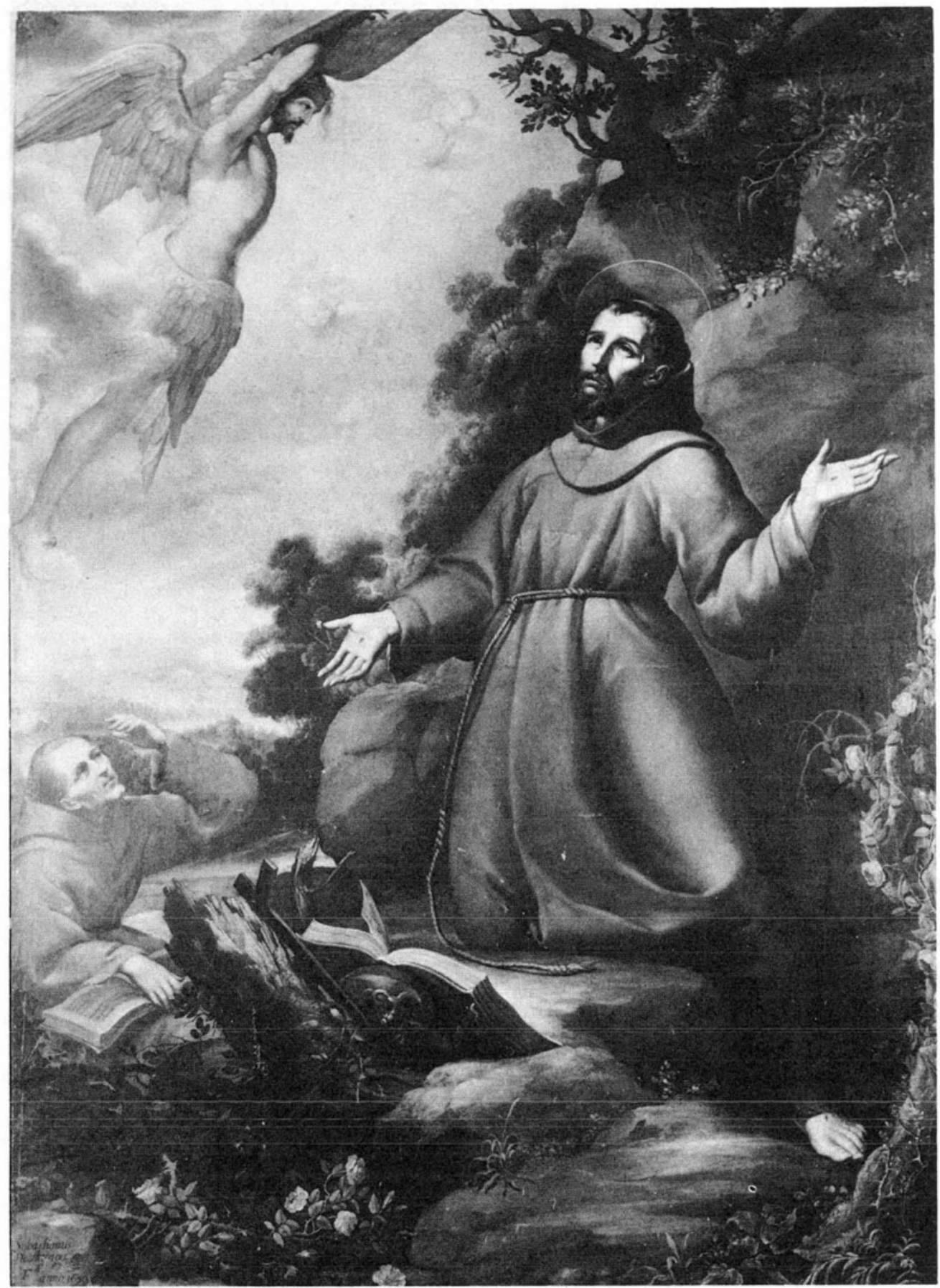

Lámina 1. Sebastián de Arteaga, Estigmatización de San Francisco, 1650; óleo sobre tela. 


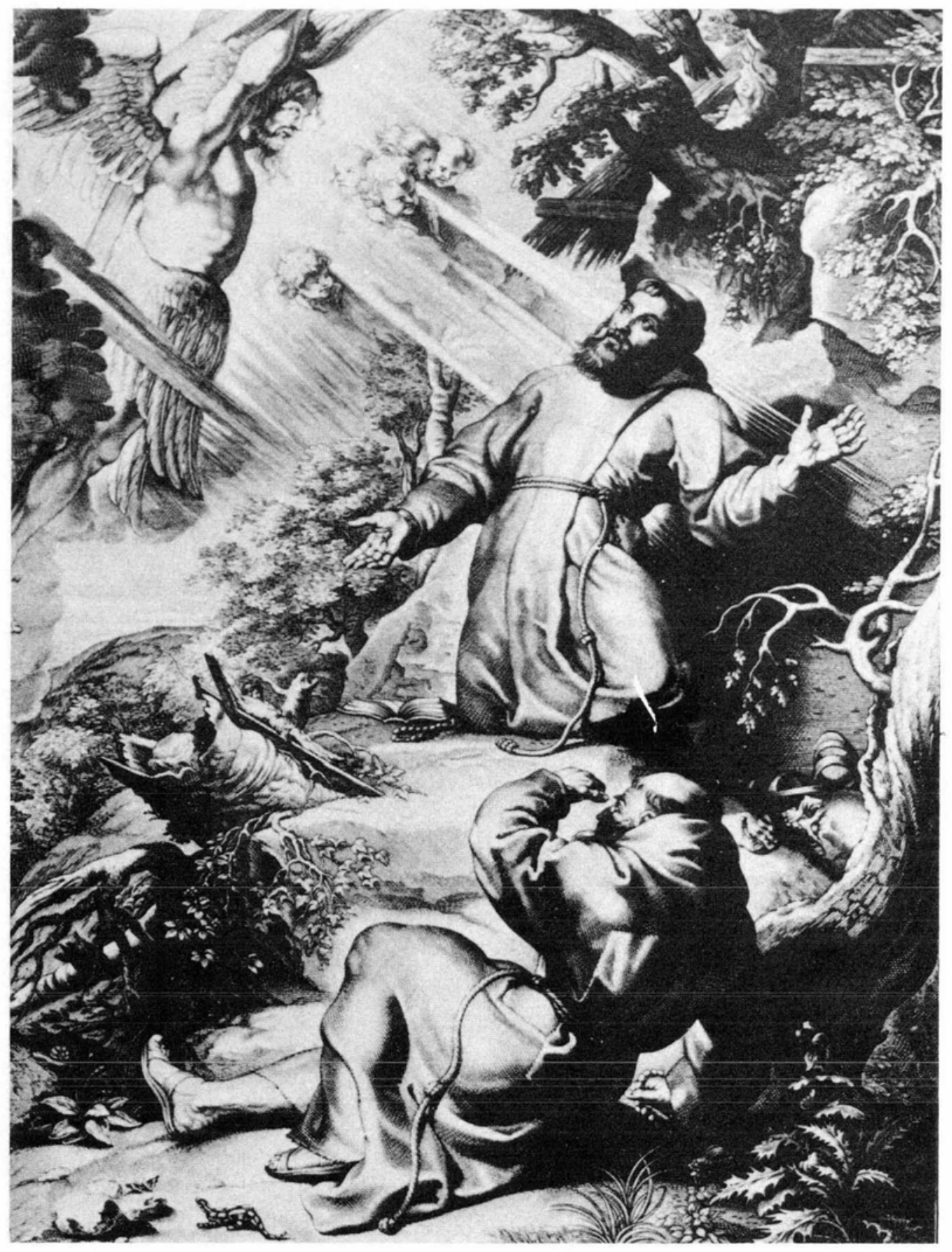

Lámina 2. Lucas Vorsterman, Estigmatización de San Francisco; grabado. 
DOI: http://dx.doi.org/10.22201/iie.18703062e.1982.50\%20Tomo\%201.1140

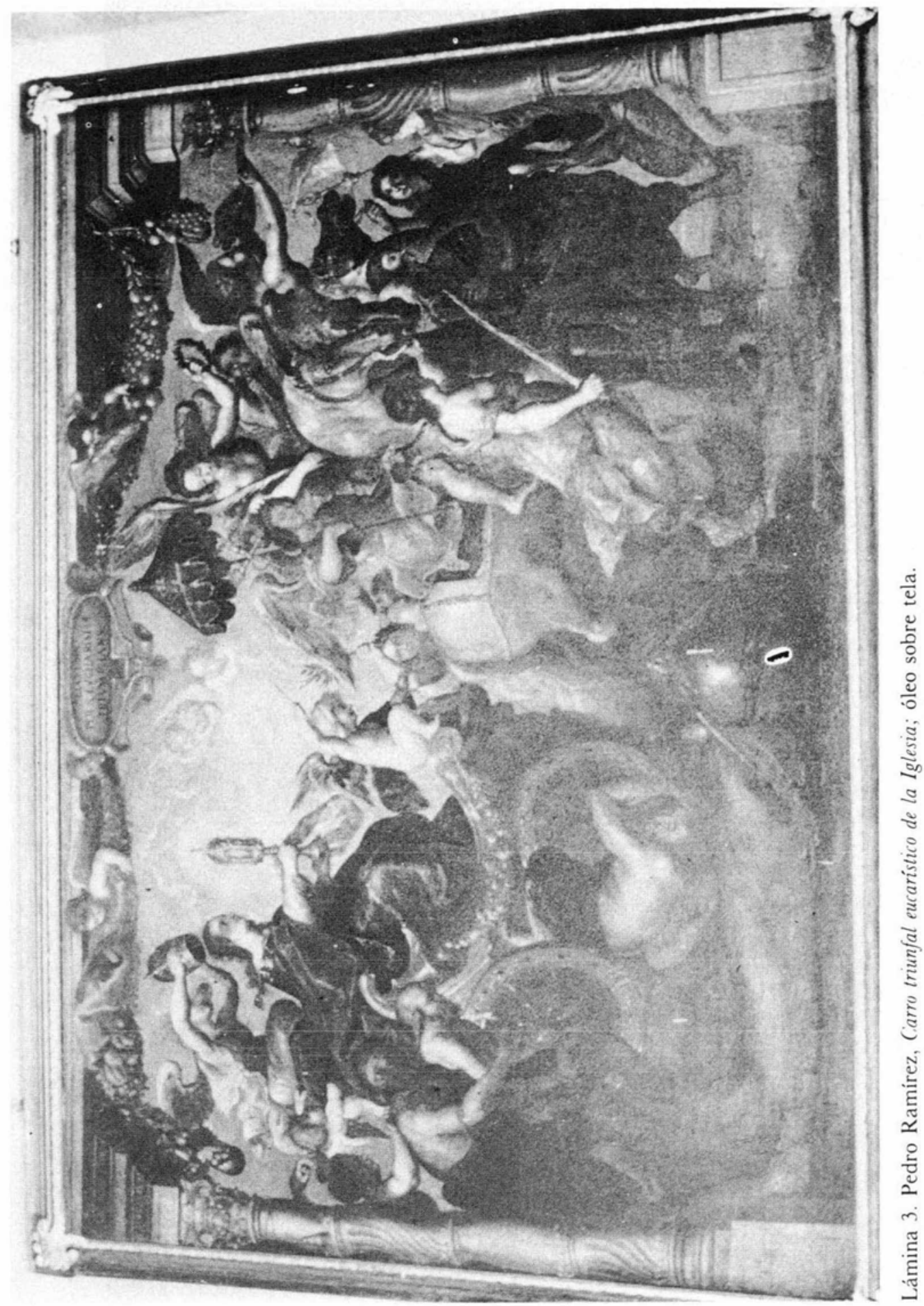


DOI: http://dx.doi.org/10.22201/iie.18703062e.1982.50\%20Tomo\%201.1140

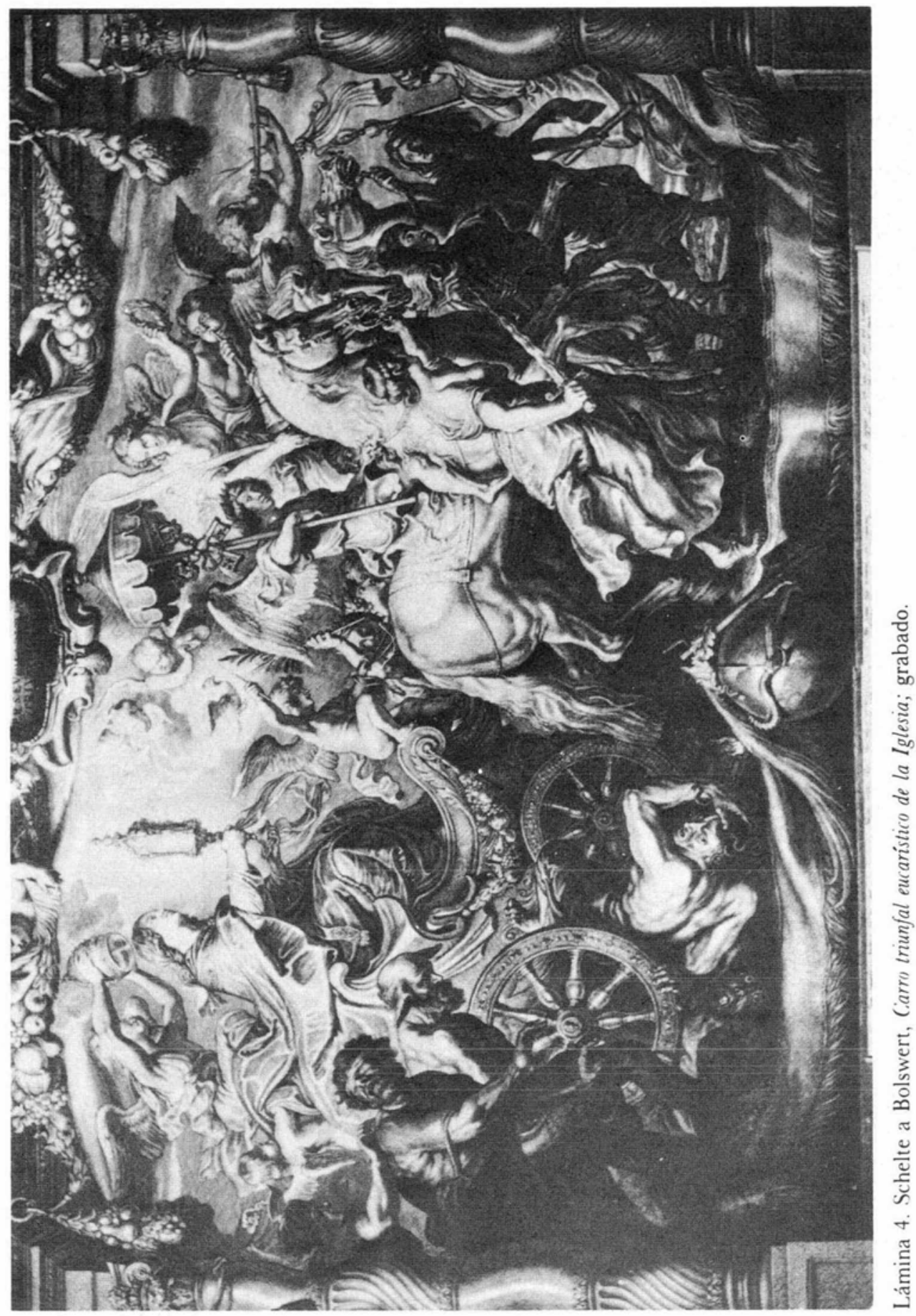




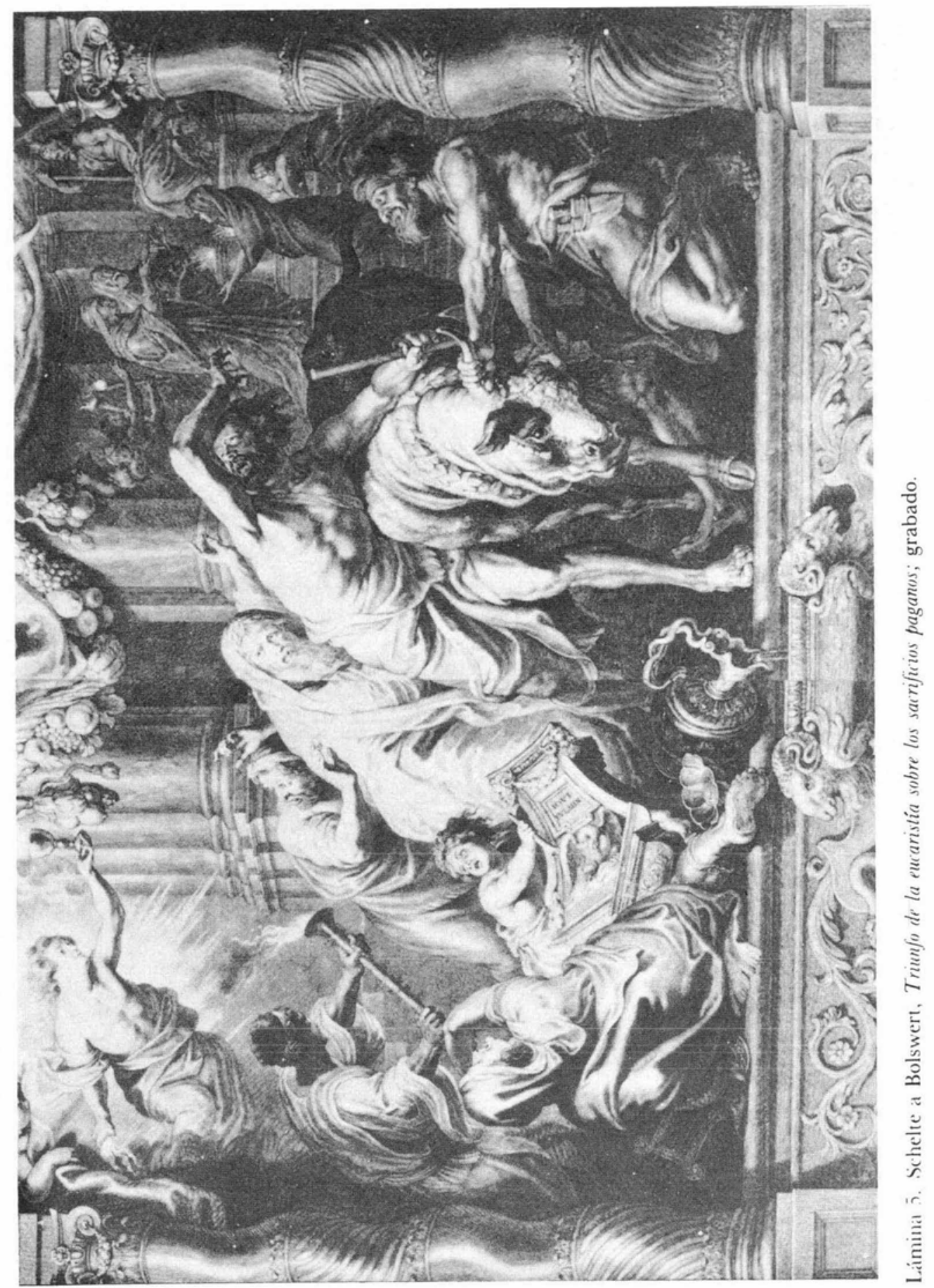




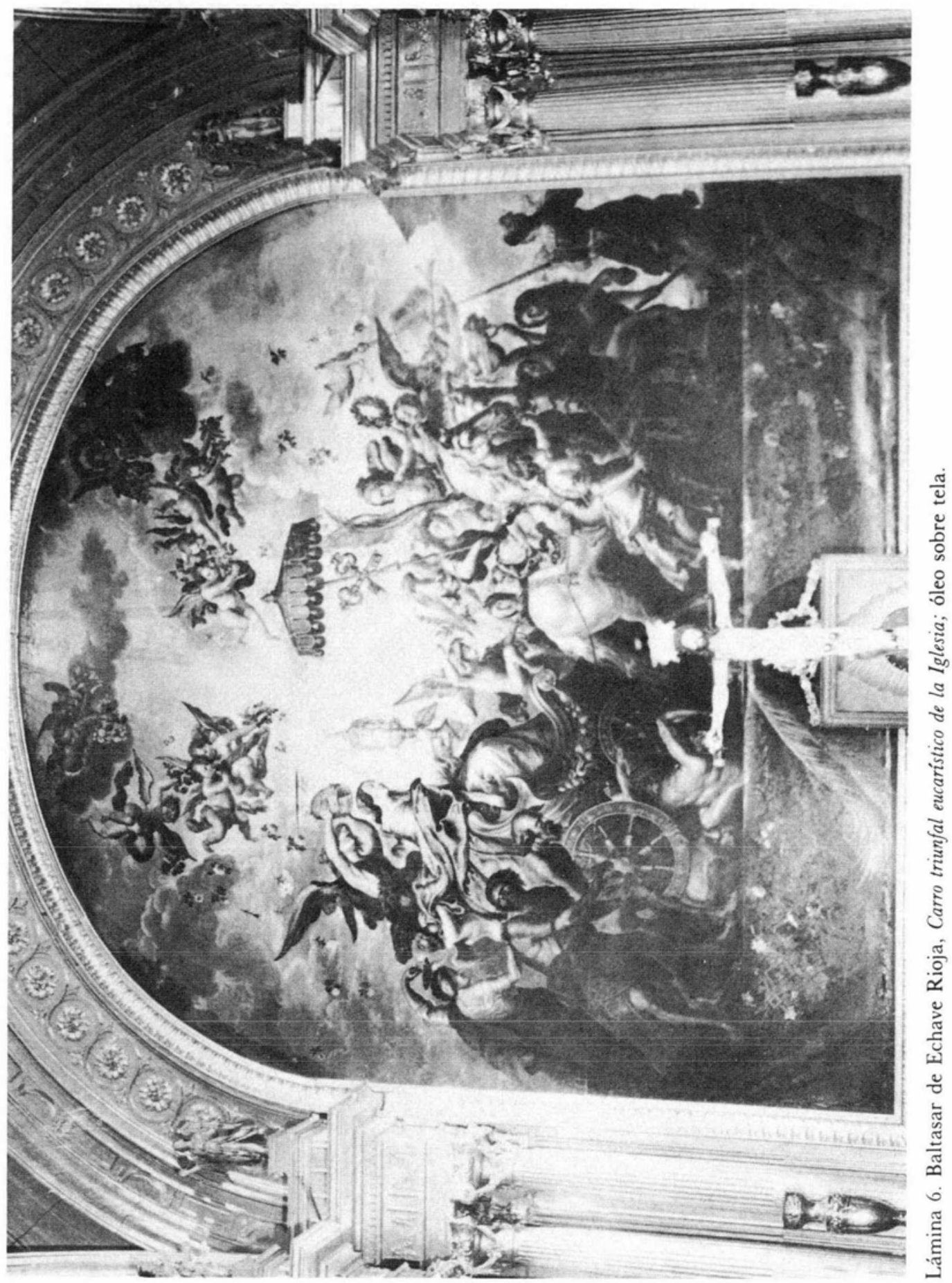




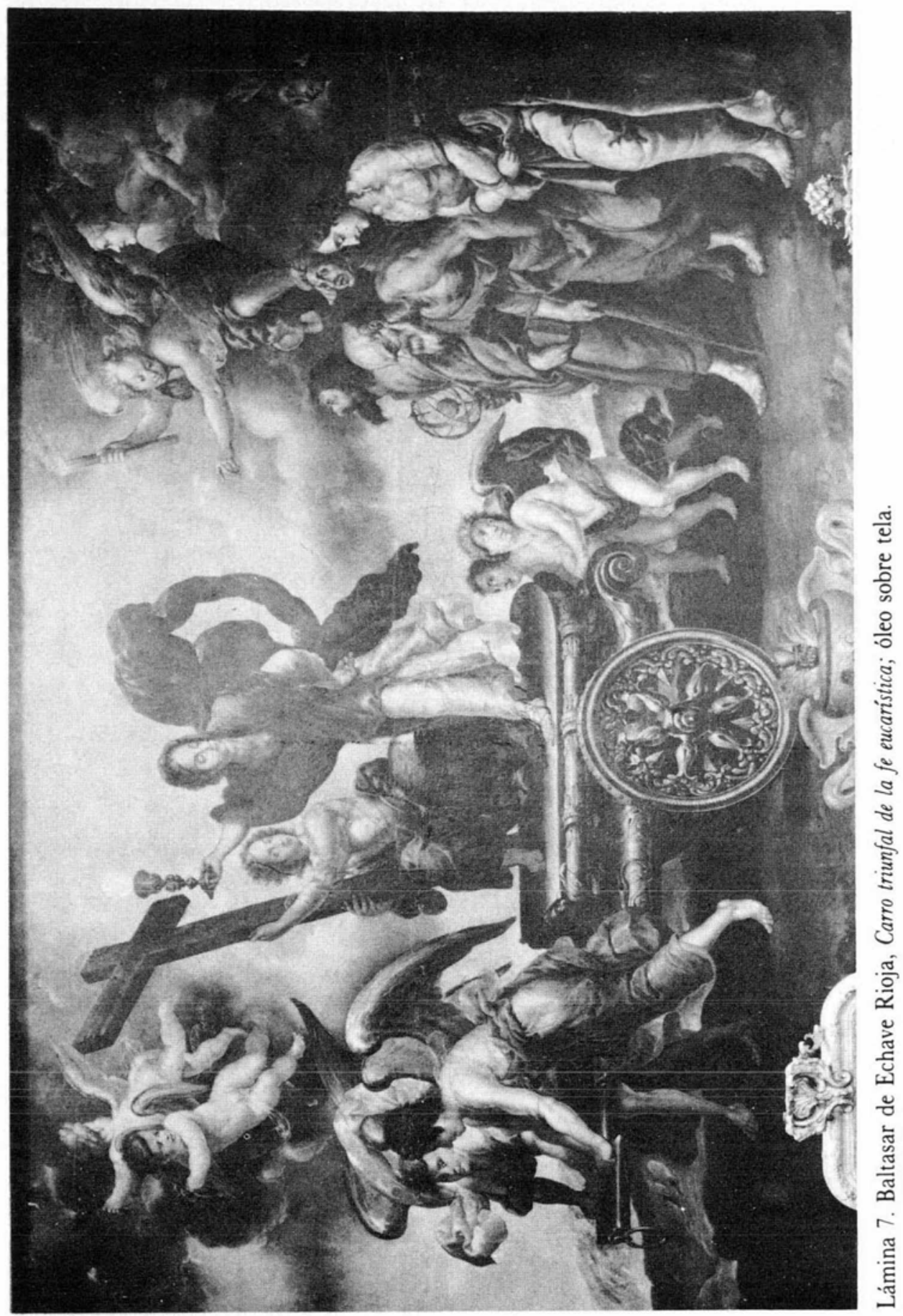


DOI: http://dx.doi.org/10.22201/iie.18703062e.1982.50\%20Tomo\%201.1140

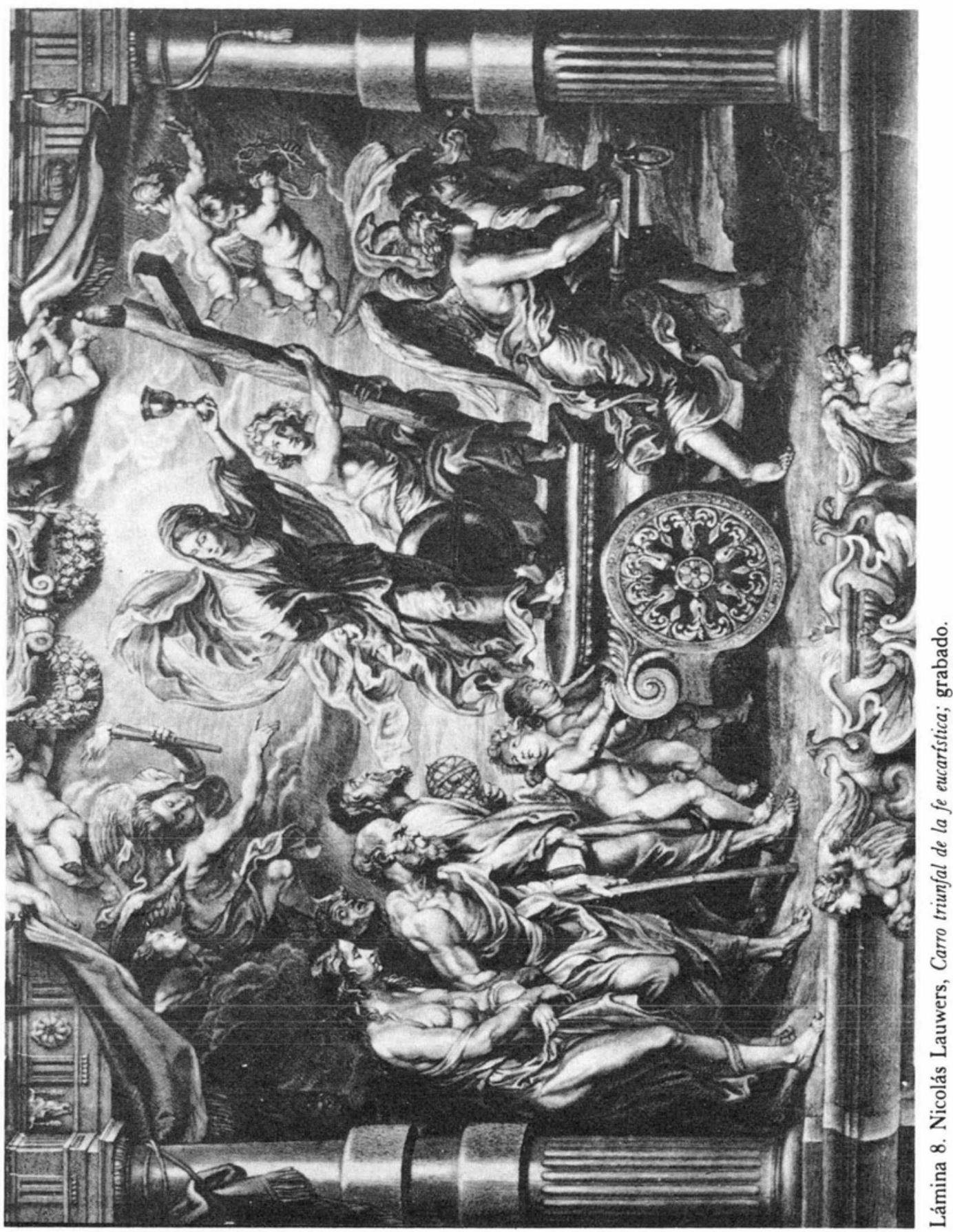


El primero de ellos, llamado también "El triunfo de la Eucaristía sobre la Ignorancia" es una transcripción bastante fiel del modelo. La iglesia, representada por una matrona, aparece en un carro triunfal sosteniendo el ostensorio eucarístico que es adorado por angelitos, a los que Ramírez ha representado con más consistencia; un ángel mancebo le tiene una tiara sobre la cabeza y un ángel niño le lleva la cauda del manto. Delante, otro con un látigo, lleva las riendas de los cuatro caballos puestos en una sola fila, cual cuadriga, que tres mujeres conducen de las bridas - acaso las tres virtudes- Sobre el primer corcel va montado un ángel mancebo sosteniendo una especie de sombrilla (símbolo procesional de las iglesias con dignidad de basilica $=$ "Konopeo") en cuyo palo se cruzan las llaves, símbolo de la dignidad pontificia. Atrás de la comitiva, cual si fueran uncidos, caminan la ceguera y la ignorancia (con venda en los ojos y largas orejas de burro, respectivamente), a los cuales quiere dar alguna luz, con una lamparilla, el Genio de la luz, representado por una mujer. En lo bajo una esfera del mundo abrazada por la sierpe que se muerde la propia cola, símbolo de la eternidad. El grabado hecho sobre esta composición es uno de los mejores de toda la escuela de Rubens, y se debe a Schelte a Bolswert

El segundo cuadro de Ramírez, el de La Eucaristía y los sacrificios del paganismo, también reproduce casi literalmente la composición rubeniana; en él vemos a un ángel mancebo que desciende en una entrada de gloria con el cáliz y la hostia ecuarísticos triunfante sobre el paganismo que está representado por los sacrificios cruentos y los incruentos. El sacrificio cruento de un toro ocupa el primer término, al tiempo que en alto y en segundo término, un sacrificio incruento es ofrendado a la estatua idolátrica de Júpiter a súplica de una dama. La sangre del toro en el uno y el comestible en el segundo, pudieran entenderse como prefiguraciones eucarísticas. Al igual que en el caso anterior, el grabado fue ejecutado por Schelte a Bolswert. Es curioso señalar cómo Ramirez siguió en ambos casos tan fielmente las estampas, que incorporó a sus cuadros los enmarcamientos arquitectónicos, así como los angelillos, las guirnaldas y cortinas de la parte superior, elementos que si bien en los tapices de Rubens cumplian una finalidad, ahora quedaban sin ninguna razón, a no ser la simplemente decorativa

No es el caso de las pinturas de Baltasar de Echave y Rioja en la sacristía de la catedral de Puebla, que repiten estos mismos temas pero éstas sí con algunas modificaciones

Echave y Rioja, el tercero de los pintores novohispanos que firmaron sus obras con el mismo nombre de "Baltasar de Echave", nació en la ciudad de México donde fue bautizado en octubre de 1632. Se dice que fue discípulo de Sebastían de Arteaga y así parece mostrarlo el claroscuro y barroquismo de su pintura En 1665 aparece valuando unos cuadros y un año después lo encontrámos envuelto en cuestiones de dineros con el Santo Oficio Murió de 50 años, el 14 de enero de 1682, y fue enterrado en el convento de San Francisco. No testó, probablemente no tenía de qué 
El primer cambio importante que percibimos en relación a los modelos, es que en estos cuadros de la sacristía poblana han desaparecido los enmarcamientos arquitectónicos, y tampoco aparecen las guirnaldas de frutas, las cortinas colgantes ni los angelillos que las sujetan. E incluso, en el del Carro Triunfal eucarístico de la Iglesia, Echave ha terminado las figuras en los extremos laterales que aparecían cortadas u ocultas por las columnas en los modelos rubenianos; este cuadro, seguramente por adaptarse al testero de la sacristía de la mencionada catedral, cierra en medio punto, para lo cual Echave se vió precisado a agr egar un celaje de fondo con angelillos esparciendo flores en la parte alta, así como una entrada de gloria insinuada en el cenit Como el cuadro presenta más espacio hacia arriba, Echave ha podido alargar la vara de la especie de sombrilla que lleva el ángel que va montado en el primer caballo, y así consigue aligerar un poco la estrechez que se siente en el original; asimismo, el suelo aparece ahora cubierto de flores. Como no podia desentenderse de la tradición y gusto propio de la Nueva España, ni de las condiciones morales imperantes en ese medio, púdicamente cubrió los pechos de una de las mujeres que conducen a los caballos, y de la matrona alada, símbolo de la victoria que porta una palma y una corona de laurel.

En el cuadro de El triunfo de la eucaristía sobre el paganismo. Echave no sólo eliminó las columnas salomónicas de los lados, sino que, en el lado izquierdo se imaginó un elevado pedestal que sirve de arranque a una sobria columna; el resto de la composición la mantuvo sin variantes importantes.

Pero hay un tercer cuadro, que aunque Revilla lo pensó, éste sí, original de Echave ${ }^{21}$ también sale de la serie rubeniana diseñada para los tapices de las Descalzas Reales. Lleva por título Carro triunfal de la fe eucarística y presenta un desarrollo más extendido en sentido horizontal en relación al modelo, gracias a lo cual Echave pudo separar más a sus figuras y aligerar un tanto lo constreñido de la composición original; la superficie del carro es ahora más grande y se aprecian mejor los angelillos que lo empujan, mismos que en el modelo quedaban bastante apretados por el grupo de figuras que camina atrás, que representan a la ciencia, la naturaleza, la fisiología, la poesía y al hombre de color La composición rubeniana fue grabada por Nicolás Lauwers.

Algo importante de estos tres cuadros de la sacristía angelopolitana es que se ha localizado el contrato mediante el cual Echave Rioja se comprometió a hacer los lienzos arriba descritos - el documento sólo habla de dos, y no de los tres que ahora existen, aunque quizá se haya realizado otro contrato para la ejecución del mayor-; ahí se mencionan los temas: ambos serían sobre el "Triunfo de la Iglesia", el uno contra la gentilidad y el otro contra el judaísmo; se especifica que deberían de medir ocho varas y media de ancho cada uno, y dice a la letra; "que ha de tener, puestos y entregados..., costeando todo lo necesario de lienzos y pintura en todo arte y perfección, conforme a dos estampas, que... se le han entregado..., dentro de cuatro meses" Trabajo por

21 (1). al, p 82 
el cual cobraría mil doscientos pesos de oro común. ${ }^{22}$ No había ninguna duda al respecto, pero aunque si la hubiese habido, con lo anterior habría quedado disipada; para la elaboración de dichos cuadros se le facilitaron al artista dos estampas, y conforme a ellas tenía que componer los cuadros que se le encargaron

Antes de terminar no está de más insistir en la enorme diferencia que existe entre un grabado y una pintura. Por principio de cuentas cada arte tiene su propio lenguaje expresivo que implica métodos y técnicas diferentes para cada caso, y así una litografía por ejemplo, exige ser considerada eso, y no tiene porque juzgársele como si fuera dibujo a lápiz, y los rasgos de buril, no tienen que competir con los trazos de una pluma o un pincel. Cada arte tiene su terreno propio y cuenta con leyes y limitaciones propias; exigen, por tanto, tratamiento específico o peculiar. En el grabado la línea se erige en soberana y adquiere una fuerza de expresión que en la pintura dificilmente alcanza; por su parte en la pintura el color tiene un campo que le es inherente y peculiar. Asi pues, la copia de grabados en el ámbito de la pintura colonial, que siempre se ha criticado y entendido como falta de originalidad, debemos entenderla como algo normal y no necesariamente negativo, toda vez que incluso en el mismo Viejo Mundo, sabemos que fue un recurso frecuentemente usado por los grandes maestros. Por otra parte, el artista que sigue un modelo grabado, tiene que inventar, crear, el colorido que este le niega, resultando a la postre obras que utilizan sus propios recursos expresivos, que aunque semejantes en el diseño son diferentes en su naturaleza.

Hemos arribado al final de nuestro camino. Por lo asentado podemos constatar la presencia de Rubens en la pintura mexicana del período virreinal desde el segundo tercio del siglo XVII Ahora podemos concluir que su presencia se dejó sentir básicamente en la repetición de sus esquemas, los cuales eran transmitidos a partir de los grabados que copiaban sus composiciones. De tal suerte que inútil seria el pretender encontrar en las pinturas de estas latitudes, ya no digamos el cromatismo vivaz, la grandilocuencia expresiva o el virtuosismo en el manejo del pincel de que hacía gala el maestro flamenco, pero ni siquiera el brio de sus trazos, el dinamismo de sus encuadres compositivos o la riqueza de su repertorio temático, y mucho menos aun su fastuosa y mundana visión de la vida, la penetrante introspección psicológica de sus retratos, su desenfado casi pagano al evocar el mundo mitológico, ni la exaltación religiosa a la que Rubens desembocó, acorde al espíritu barroco postridentino que le tocó vivir

Es necesario convenir, pues, que su influjo o presencia se redujo al empleo

22 Francisco Pérez Salazar Hisloria de la pintura de Puebla, México, UNAM, 1963, p. 178-179 El contrato está hecho el 25 de marzo de 1675. Revilla afirma que "fueron tomadas de dos preciosas láminas de Rubens", y agrega en nota que para ese entonces eran propiedad de don Alejandro Ruiz conocido coleccionista de obras de arte, residente en la misma ciudad de Puebla 
de sus esquemas compositivos, y aún esto sólo de aquellas composiciones que fueron trasladadas al buril. Cabría el preguntarse qué habría de Rubens en el medio pictórico novohispano si no hubiesen sido reproducidos en estampas muchos de sus cuadros, y estos grabados no hubiesen llegado a estas latitudes. A este respecto es necesario pensar que si se copiaron las composiciones de los cuadros de Rubens, esto no quiere decir que hubiese existido alguna predilección o interés especial por su obra o estilo, sino porque sus esquemas fueron ampliamente difundidos en el vehículo fácil de las estampas. Y es que, la verdad sea dicha, los artistas del Nuevo Mundo copiaban indistintamente los grabados que llegaban a sus manos.

En los casos que acabamos de ver, considero que, quien más, quien menos, toman el modelo pero, cuando no le añaden elementos nuevos, suprimen otros, achican unas formas y alargan otras, suprimen figuras o incorporan nuevas; pero sobre todo, se atreven a interpretar a "su propio gusto" los paños, rostros, manos, etc,; gusto que remite invariablemente al contexto que les pertenece, de tal manera que incorporan las modificaciones que consideran pertinentes a fin de que sus obras respondan al gusto y tradición del medio que les es propio. Para terminar podemos recordar la reflexión que hacia un estudioso de estos asuntos: "al estudiar las fuentes primigenias y compararlas con las formas derivadas de ellas, podemos averiguar no sólo la difusión que alcanzaron las obras del Viejo Continente en el nuestro, sino también un mejor conocimiento de las predilecciones estéticas y temáticas en esa etapa de la actividad artística americana". 23

${ }^{23}$ Ricardo Toledo Palomo "Aportaciones del grabado europeo al arte en Ciuatemala", e Anales del Instututo de Invesirgatumes Estétzas, No 35, México, UNAM1, 1966, p. 47 
DOI: http://dx.doi.org/10.22201/iie.18703062e.1982.50\%20Tomo\%201.1140

\section{BIBLIOGRAFIA}

CARRILLO Y GARIEL, Abelardo. Tremua de la pintura de Vuez a España, México, UNAM, I I.E., 1946

COCHET, Gustavo El grabado (Histoma) Térmca), 2a ed, Buenos Aires, Editorial Poseidón, 1947, (Colección todo para todos, Manuales de divulgación Artes, Ciencias, Oficios)

FERNÁNDEZ, Justino. "Rubens y José Juárez" en Anales del IIE. No. 10, México, UNAM, 1943.

HAUSSER, Arnold Mlstoria soctal de la literatura y el arle, 2a ed, 2t, Madrid, Ediciones Guadarrama, 1962

HIND, Arthur M t hivery of engraing etheng from the 15 th entury to the year 1911 , New York, Dover Publications, Inc 1963.

MICHELET TI, Emma Rubens, Italia, Instituto Geográfico de Agostini-Novara, 1966

PEREZ SALAZAR, Francisco. Historia de la pintura en Puebla, Edición, introducción y notas de Elisa Vargas Lugo, México, UNAM, I I E, 1963, (Estudios y Fuentes del arte en México, $\mathrm{XIII)}$

STASNY, Francisco. La presencia de Rubens en la Plntura Colonial, Lima, 1965, (Sobretiro de la Reivia Peruana de (ullura, No 4, enero, 1965)

TOLEDO PALOMO, Ricardo "Aportaciones del grabado europeo al arte de Guatemala" en tnales del Inslliulo de Impsilgacones Estéticas, No 35, México, UNAM, 1966.

TORMO, Elías "La Apoteosis eucarística" Rubens. los tapices de las descalzas reales de Madrid, en archivo Español de arte, No 49, Madrid, Instituto Diego Velázquez, enero-febrero, 1942

TORRE REVELLO, Jorge "Obras de arte enviadas al Nuevo Mundo en los siglos XVI y XVII", en Anales del Institulo de Arte Americano e Investigaciones Estéticas, No 1, Buenos Aires, 1948.

ToUssaint, Manuel Pintura colonial en México, México, UNAM, I I E, 1965

WESTHEIM, Paul Ei grabado en madera, 2a ed, México, FC E, 1967. (Breviario 95)

VIEGHE, Hans. Saints I, Londres, 1972 (Corpus Rubenianum, L Burchard, VIII) 